\title{
A cost-effective approach for abatement of cyanide using iron-impregnated activated carbon: kinetic and equilibrium study
}

\author{
Shelja Agarwal ${ }^{1} \cdot$ Sabyasachi Pramanick ${ }^{1}$ Sheik Ajanur Rahaman ${ }^{1} \cdot$ Kartik Chandra Ghanta $^{1} \cdot$ Susmita Dutta $^{1}$ (D)
}

Received: 28 November 2018 / Accepted: 12 April 2019 / Published online: 26 April 2019

(c) The Author(s) 2019

\begin{abstract}
The present study is devoted for eliminating cyanide from wastewater through adsorption onto a surface impregnated with iron. It is seen that the impregnation of iron improves the removal efficacy of cyanide. Ferric nitrate nonahydrate has been used as impregnating agent, and Corncob, a waste material, has been used as a progenitor for the preparation of adsorbent. For determining the optimum conditions for impregnation of iron, response surface methodology has been employed. Combined effect of weight ratio, time, and temperature has been tested, and optimum condition has been obtained with weight ratio (1.0), time $(1.50 \mathrm{~h})$, and temperature $\left(400{ }^{\circ} \mathrm{C}\right)$, and the sample made at this condition is named as iron-impregnated activated carbon (IIAC). While studying the adsorptive behavior of IIAC in contrast to activated Corncob without impregnation (ACWI), it has been found that for a cyanide solution of $50 \mathrm{mg} \mathrm{L}^{-1}$, ACWI can remove only $61 \%$ of cyanide and IIAC is able to remove around $91 \%$ at a constant adsorbent dosage of $10 \mathrm{~g} \mathrm{~L}^{-1}$. The minimum $(-1)$ and maximum $(+1)$ level of particle sizes $(45-150 \mu \mathrm{m})$, adsorbent dosage $\left(5-20 \mathrm{~g} \mathrm{~L}^{-1}\right)$, and initial concentration (IC) of cyanide (5-50 $\mathrm{mg} \mathrm{L}^{-1}$ ) on cyanide removal have been examined using ANOVA, at room temperature $\left(25^{\circ} \mathrm{C}\right)$ for knowing the dependence on the same. Maximum cyanide removal (99.58\%) has been achieved at an optimum particle size of $100 \mu \mathrm{m}$, adsorbent dosage of $3.95 \mathrm{~g} \mathrm{~L}^{-1}$, IC of $27.5 \mathrm{mg} \mathrm{L}^{-1}$ at $\mathrm{pH} 7.5$ with IIAC. Langmuir and Freundlich isotherm models have been used for analyzing equilibrium data where Freundlich isotherm has been suitable. Different kinetic models have been employed to fit the data. Pseudo-second-order kinetic model has been found to be most applicable.
\end{abstract}

Keywords Cyanide $\cdot$ Iron-impregnated activated carbon $\cdot$ Kinetic study $\cdot$ Adsorption isotherm

\section{List of symbols}

A Weight ratio of Corncob dust to ferric nonahydrate $\left(\mathrm{g} \mathrm{g}^{-1}\right)$

$B \quad$ Time (h)

C Temperature $\left({ }^{\circ} \mathrm{C}\right)$

$K_{\mathrm{F}} \quad$ Freundlich adsorption constant $\left[\left(\mathrm{mg} \mathrm{g}^{-1}\right)\left(\mathrm{L} \mathrm{mg}^{-1}\right)^{1 / n^{\prime}}\right]$

$K_{\mathrm{L}} \quad$ Langmuir adsorption constant $\left(\mathrm{L} \mathrm{mg}^{-1}\right)$

$n_{\mathrm{c}} \quad$ Number of central run

$N \quad$ Total number of experiments

$n \quad$ Number of numeric factors

$q_{\mathrm{e}} \quad$ Adsorption capacity $\left(\mathrm{mg} \mathrm{g}^{-1}\right)$

$q_{\mathrm{t}} \quad$ Adsorption capacity at time $t\left(\mathrm{mg} \mathrm{g}^{-1}\right)$

$R^{2} \quad$ Corelation coefficient

$R_{1} \quad$ Removal of cyanide (\%) $t \quad$ Time (min)

$T$ Temperature (K)

$k_{0} \quad$ Zero-order reaction rate constant $\left(\mathrm{mg} \mathrm{L}^{-1} \mathrm{~min}^{-1}\right)$

$k_{1} \quad$ First-order reaction rate constant $\left(\mathrm{min}^{-1}\right)$

$k_{2} \quad$ Pseudo-first-order reaction rate constant $\left(\mathrm{min}^{-1}\right)$

$k_{3} \quad$ Pseudo-second-order reaction rate constant $\left(\mathrm{g} \mathrm{mg}^{-1} \mathrm{~min}^{-1}\right)$

$X_{i} \quad$ Input variables

$Y \quad$ Response

$\beta_{0} \quad$ The constant coefficient

$\beta_{i j}$ The linear-by-linear interaction effect between the input factors $X_{i}$ and $X_{j}$

$\beta_{i i} \quad$ The quadratic effect of input factor $X_{i}$

$\beta_{i} \quad$ The linear effect of the input factor $X_{i}$

Susmita Dutta

susmita_che@yahoo.com

1 Department of Chemical Engineering, National Institute of Technology Durgapur, Durgapur 713209, India 


\section{Introduction}

With industrial growth and advancement in technology, the improper disposal of industrial wastewater containing large quantities of cyanide has resulted in the contamination of water bodies. This issue not only results in unavailability of safe drinking water but also poses a threat to human health in general. Therefore, in order to render water resources safe, it is essential to remove cyanide from industrial wastewater before discharge. A vast number of chemical, physical and biological methods have been employed to treat cyanide in wastewater, but all these processes have their own drawbacks. Though different chemical methods, like alkaline chlorination (Patil and Paknikar 2000; Botz 2001), oxidation (Dhamo 1996), ozonation (Dash et al. 2006), iron cyanide precipitation (Oliveira et al. 2003), etc., have been used for cyanide removal, the common drawbacks posed by these processes include high chemical cost, huge amount of sludge generation, difficulty in disposal of the precipitates, etc. Cyanide removal with the aid of bacteria has been investigated by the researchers over decades (Gurbuz et al. 2004). But a biological process calls for a pre-treatment, because if microbes are added to very toxic waste, its life may be hampered. Thus, pre-treatment adds up as an additional cost to waste treatment. Hence there is a need for a single-step waste treatment process which does not require any pre- or post-treatment (Gonzalez et al. 2018). Here is when adsorption comes into play. Adsorption shows properties that can aid waste removal in a single step with minimal inflexion of resources. Adsorption is one of the most favored wastewater treatment techniques for all practical purposes; it is not only eco-friendly and sustainable, but also economic (Priyanka and Saravanakumar 2018). Again when the purpose is to treat waste, the use of very expensive adsorbents (commercial activated carbon) is not favorable. There are a variety of adsorbents available in the field of adsorption study but choosing the right adsorbent is tedious. Commercial activated carbon is a preferred material as adsorbent, for the expulsion of pollutants from water due to its large surface area, high adsorption capacity, and microporous structure, but the regeneration cost of adsorbent is high. This has led to search of a cheaper and suitable adsorbent for selective adsorption process. The present study uses waste Corncob as precursor for preparation of adsorbent for the removal of cyanide. Corncob is essentially a waste, and thus, inexpensive. Adsorption is inherently concerned with the development of a very large surface; hence improvement in Corncob's surface poses an important question. In the present study, Corncob is impregnated with iron to improve the adsorption efficiency of Corncob. As per the knowledge of present research group concerned, no work has been done with Corncob as a precursor for preparation of activated carbon and application of the prepared adsorbent in cyanide removal.

\section{Materials and methods}

\section{Selection and preparation of adsorbent}

In the present study, Corncob was chosen as the precursor for preparation of adsorbent to remove cyanide, which was collected from a local market in Durgapur, West Bengal. After that, it was made moisture free in a hot air oven at $50{ }^{\circ} \mathrm{C}$ for 3-4 days. It was then crushed in a Jaw crusher and grinded in a grinder to get very fine-sized particles. The material was then screened for getting particle size of $500 \mu \mathrm{m}$. The Corncob dust $(500 \mu \mathrm{m})$ was mixed with ferric nitrate nonahydrate (Extra Pure, LOBA Chemie, India) and taken in several heat resistant silica crucibles. The crucibles were placed in a Muffle furnace operated at particular temperature. Optimum condition for carbonization was assessed using response surface methology (RSM). After a certain time, the crucibles were taken out from the muffle furnace and kept in a desiccator for cooling. It was then washed with distilled water for removal of any loosely bound metal ions using vacuum pump. It was then taken in a Petri plate and kept in the hot air oven (Universal Hot Air Oven) at a temperature of $50{ }^{\circ} \mathrm{C}$. Finally, prepared adsorbent was screened for obtaining adsorbent having different particle size. The prepared adsorbent at optimum condition was called ironimpregnated activated carbon (IIAC). Another set of absorbent was prepared following the same process but without using any impregnation (ferric nitrate nonahydrate) and was named as activated carbon without impregnation (ACWI).

\section{Experimental design}

RSM is a methodology for obtaining optimum values of any process in which response of interest is affected by numerous variables (Dutta et al. 2011). Three steps were followed to carry out the optimization viz., performing the statistically designed experiments, estimating the coefficients using a mathematical model, predicting the responses, and studying the efficacy of the model. An RSM model facilitates the linkage of input variable factors $\left(X_{i}\right)$ and output variable $(Y)$.

$Y=f\left(X_{1}, X_{2}, X_{3}, \ldots \ldots \ldots \ldots \ldots, X_{n}\right)$

Central composite design (CCD) is an RSM design, which was used to fit surface (quadratic) and thus optimize the effective parameters with a minimum possible number of experiments. It also helps in studying the relation between the parameters (Sen et al. 2018). The CCD generally consists 
of $2^{n}$ factorial runs with $2 n$ axial runs and $n_{\mathrm{c}}$ central runs (Chaterjee et al. 2012). Experimental errors and the repeatability of the experiment was obtained with the aid of center points. Therefore, for the carbonization process having three numeric factors, total experiments to be performed is given by:

$N=2^{n}+2 n+n_{C}=2^{3}+(2 \times 3)+6=20$

Randomized order of experimentation was used to assess the influence of independent factors. The result of each run was analyzed, and the response was related to three input factors for carbonization of Corncob through an empirical polynomial (second-degree) equation given as:

$Y=\beta_{0}+\sum_{i=1}^{n} \beta_{i} X_{i}+\sum_{i=1}^{n} \beta_{i i} X_{i}^{2}+\sum_{i=1}^{n} \sum_{j=1}^{n-1} \beta_{i j} X_{i} X_{j}$

where $Y, \beta_{0}, \beta_{i i}, \beta_{i}, \beta_{i j}$ stand for predicted outcome, constant coefficient, quadratic coefficients, linear coefficients, and interaction coefficients, respectively (Dutta et al. 2011).

The system represented by independent parameters and dependent output response was modeled and statistical parameters were evaluated using ANOVA. The maximum $(+1)$ and minimum $(-1)$ level of the weight ratio of Corncob dust to ferric nitrate nonahydrate, temperature, and time of carbonization were $3.0-1.0,500-400{ }^{\circ} \mathrm{C}$, and 1.50 to $1.00 \mathrm{~h}$, respectively. This design was followed while carrying out the experiments. Carbonization for $1.50 \mathrm{~h}$ at $400{ }^{\circ} \mathrm{C}$ temperature with 1.0 weight ratio was found to be optimum. The sample, thereafter, obtained was called IIAC and was used for further studies on cyanide abatement. To examine the role of iron onto the prepared adsorbent, Corncob dust was carbonized at the same temperature and time of carbonization as that of IIAC but, without iron impregnation. The sample, thus, formed, was termed as activated carbon without impregnation (ACWI).

\section{Characterization of IIAC}

The physicochemical characterization of IIAC was carried out by conventional methods. For the characterization of iron-impregnated activated carbon, a particle size of $100 \mu \mathrm{m}$ was maintained. Scanning electron microscopy (SEM) study generates images of samples. It scans the surface of the sample with the aid of a focused beam containing electrons. An interaction between electrons and atoms of the sample takes place, hence producing signals that give an idea about the topography of the sample surface. SEM study was done before and after adsorption of cyanide onto the surface of IIAC using scanning electron microscope (JEOL JSM5800-Oxford EDS Detector). Energy-dispersive spectroscopy (EDS) is a technique used to find out the composition of materials with the help of X-ray. EDS analysis generates a spectra with peaks of the elements present in the sample under observation. EDS study of IIAC before and after adsorption of cyanide was done using the same instrument. Fourier transform infrared spectroscopy study (FTIR) (instrument model NEXUS-870) was used to observe the functional groups involved in the abatement of pollution.

\section{Comparative study on removal of cyanide using IIAC and ACWI}

To examine the efficacy of IIAC and ACWI, a comparative study was conducted. Cyanide solution of $50 \mathrm{mg} \mathrm{L}^{-1}$ was prepared from a standard $1000 \mathrm{mg} \mathrm{L}^{-1}$ cyanide solution (Merck KGaA, 64271 Darmstadt). The adsorbent dose of $10 \mathrm{~g} \mathrm{~mL}^{-1}$ was maintained for both the cases, with a shaking speed of $150 \mathrm{rpm}$, and the time of adsorption was kept constant at $3 \mathrm{~h}$. Residual cyanide was analyzed by Orion ion meter (Orion Star Series, B36531).

\section{Effect of operating variables on the abatement of cyanide aided by IIAC and kinetic study}

For studying the effects of IC of cyanide $\left(5-50 \mathrm{mg} \mathrm{L}^{-1}\right)$, particle size of adsorbent $(45-150 \mu \mathrm{m})$, and adsorbent dosage (5-20 $\left.\mathrm{g} \mathrm{L}^{-1}\right)$ on cyanide removal, synthetic wastewater was made by diluting the standard solution of cyanide using distilled water. Synthetic solution $(50 \mathrm{~mL})$ was taken in each case and $0.5 \mathrm{~g}$ of IIAC was added to the solution. The solution was then kept in the incubator shaker (Modern instruments, Kolkata, India) at $150 \mathrm{rpm}$ for $3 \mathrm{~h}$ at $25^{\circ} \mathrm{C}$. Samples were collected after definite time gap, and they were centrifuged at $5000 \mathrm{rpm}$ for $15 \mathrm{~min}$ to segregate impregnated activated carbon and the solution. Residual cyanide in solution was analyzed by Orion ion meter.

\section{Equilibrium study for the removal of cyanide}

For equilibrium study, volume, adsorbent dosage, and time were kept constant for each case as $50 \mathrm{~mL}, 10 \mathrm{~g} \mathrm{~L}^{-1}$, and $3 \mathrm{~h}$, respectively. Cyanide solution of different $\mathrm{IC}$ was taken, and $0.5 \mathrm{~g}$ of adsorbent was added to the $50 \mathrm{~mL}$ of solution. It was covered and placed in the incubator with shaker. After $3 \mathrm{~h}$, samples were collected and were centrifuged. The sample was analyzed by Orion ion meter to determine the equilibrium concentration.

\section{Optimization of cyanide removal aided by IIAC using RSM}

IIAC was used for the study of removal of cyanide from the aqueous solution. All experiments were performed according to the statistical design as prepared by Design-Expert Software (version 8.0.7.1, Stat-Ease, Minneapolis, USA).

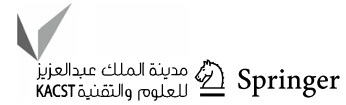


The goal of optimization of cyanide removal from aqueous solution by adsorption process in batch mode of operation is to minimize the adsorbent dosage and to increase the IC of cyanide. Three input parameters such as IC of cyanide, adsorbent dosage, and $\mathrm{pH}$ were varied, and removal of cyanide was considered as response. The maximum $(+1)$ values of input parameters were $12 \mathrm{~g} \mathrm{~L}^{-1}, 35 \mathrm{mg} \mathrm{L}^{-1}$, and 8 for adsorbent dosage, IC of cyanide, and $\mathrm{pH}$, respectively, and the minimum $(-1)$ values of the input parameter were $6 \mathrm{~g} \mathrm{~L}^{-1}, 20 \mathrm{mg} \mathrm{L}^{-1}$, and 7 for adsorbent dosage, IC of cyanide and $\mathrm{pH}$ at $25^{\circ} \mathrm{C}$. For better results, continuous mixing was provided during experimentation. The remaining cyanide concentration was measured by Orion ion meter.

\section{Results and discussion}

\section{Preparation of activated carbon under optimal condition}

RSM has been used to optimize the carbonization condition of Corncob using ferric nitrate nonahydrate as impregnating vis-à-vis activating agent. The samples have been prepared at each experimental condition as shown in Table 1. The samples have been contacted with simulated solution of cyanide and percentage removal of cyanide has been placed in the corresponding rows of the fourth column of the said table. A quadratic model suggested by the software has been used to fit the data. The equation is given by:

$$
\begin{aligned}
R_{1}= & 52-15.04 A+4.82 B C-2.17 C-9.12 A B+0.13 A C \\
& -6.87 B C+1.30 A^{2}+10.34 B^{2}-5.29 C^{2}
\end{aligned}
$$

where $R_{1}$ is the response given as the removal of cyanide, $A$ is the weight ratio of Corncob dust to ferric nitrate nonahydrate $\left(\mathrm{g} \mathrm{g}^{-1}\right), B$ is time $(\mathrm{h})$, and $C$ is the temperature $\left({ }^{\circ} \mathrm{C}\right)$.

The values of statistical parameters are: $R^{2}=0.9675$, $R_{\text {Adj }}^{2}=0.9383$, and $R_{\text {Pred }}^{2}=0.7511$. Actual responses are obtained by experimentation and predicted responses are generated using the model. The $R^{2}$ is given as the ratio between the variation suggested by the model and the total variation of the data obtained through experimentation. Larger value of $R^{2}$ is suggested as it implies the percentage of variability in the response explained by statistical model (Silva et al. 2004). Thus, the high values of $R^{2}$ and $R_{\text {Adj }}^{2}$ ensures the aptness of the predicted model.

It is observed from Table 1 that percentage removal of cyanide at different carbonization condition (weight ratio, time, and temperature) varies from 24 to $95 \%$. Since the ratio is less than 10, no transformation is required. The combined effect of temperature of carbonization and weight ratio on percentage removal of cyanide is shown in Fig. 1a. From the figure, it has been seen that carbonization temperature is inversely proportional to removal efficiency. Percentage
Table 1 Experimental design matrix for optimization of carbonization

\begin{tabular}{lllll}
\hline Run no. & $\begin{array}{l}\text { Weight ratio (corncob dust: } \\
\text { impregnating agent) }\end{array}$ & Time (h) & Temperature $\left({ }^{\circ} \mathrm{C}\right)$ & $\begin{array}{l}\text { Cyanide } \\
\text { removal } \\
(\%)\end{array}$ \\
\hline 1 & & & & 36.03 \\
2 & 2.00 & 1.25 & 365.91 & 95 \\
3 & 1.00 & 1.50 & 400.00 & 54 \\
4 & 3.00 & 1.50 & 400.00 & 52 \\
5 & 2.00 & 1.25 & 450.00 & 55 \\
6 & 1.00 & 1.00 & 400.00 & 52 \\
7 & 2.00 & 1.25 & 450.00 & 54 \\
8 & 3.00 & 1.00 & 500.00 & 52 \\
9 & 2.00 & 1.25 & 450.00 & 52 \\
10 & 2.00 & 1.25 & 450.00 & 73.8 \\
11 & 2.00 & 0.83 & 450.00 & 58 \\
12 & 1.00 & 1.00 & 500.00 & 52 \\
13 & 2.00 & 1.25 & 450.00 & 75 \\
14 & 1.00 & 1.50 & 500.00 & 38 \\
15 & 2.00 & 1.25 & 534.09 & 24 \\
16 & 3.68 & 1.25 & 450.00 & 87.3 \\
17 & 0.32 & 1.25 & 450.00 & 88.6 \\
18 & 2.00 & 1.67 & 450.00 & 46 \\
19 & 3.00 & 1.00 & 400.00 & 30 \\
20 & 3.00 & 1.50 & 500.00 & 52 \\
\hline
\end{tabular}

لو مدينة الملك عبدالعزيز

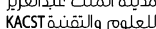


Fig. 1 Conjugate effect a weight ratio and temperature, $\mathbf{b}$ temperature and carbonization time, $\mathbf{c}$ weight ratio and carbonization time on removal of cyanide

removal of cyanide increases from 60.80 to 65.01 and from 31.10 to 35.28 when temperature is lowered from 500 to $400{ }^{\circ} \mathrm{C}$ keeping the weight ratio constant at 1.0 and 3.0, respectively. Thus, it can be stated that higher temperature is not suitable for carbonization. Further, lower removal at higher weight ratio may be due to the lower impregnation in the presence of lower amount of ferric nitrate nonahydrate. Maximum removal of $65.01 \%$ has been obtained when weight ratio and temperature of carbonization have been maintained at 1.0 and $400{ }^{\circ} \mathrm{C}$, respectively. Temperature affects the surface area of the adsorbent. Yorgun and Yildiz (2015) varied the temperature between 300 and $600^{\circ} \mathrm{C}$ with impregnation ratio between 1.0 and 4.0 using Paulownia wood. They observed that the performance of the activated carbon increased with an increase in temperature of carbonization from 300 to $400{ }^{\circ} \mathrm{C}$. Further increase in temperature led to contraction of the carbon structure. Dutta et al. (2011) observed that best carbonization results were obtained at $450{ }^{\circ} \mathrm{C}$ and at a weight ratio of 1.0 at constant time of carbonization of $1.125 \mathrm{~h}$ using peels of citrus fruits as the precursor for low-cost adsorbent preparation.

The effect of carbonization time and temperature on the percentage removal of cyanide is shown in Fig. 1b. Percentage removal increases from 47.82 to 70.48 and decreases from 56.78 to 52.68 when time is increased from 1 to $1.5 \mathrm{~h}$ at a constant temperature of $400{ }^{\circ} \mathrm{C}$ and $500{ }^{\circ} \mathrm{C}$, respectively. Increase in removal with time may be due to the enhanced carbonization for longer period. However, a drop in the removal is seen at $500{ }^{\circ} \mathrm{C}$. This may be due to excessive exposure of material at higher temperature for longer time. Furthermore, it can be said that the carbonization at higher temperature for less time is suitable, whereas carbonization at higher temperature and time is not suitable for preparation of adsorbent. Thus, a maximum removal of $70.48 \%$ has been obtained when temperature and carbonization time have been maintained as $400{ }^{\circ} \mathrm{C}$ and $1.50 \mathrm{~h}$, respectively. Sudaryanto et al. (2006) reported that role of carbonization time is very terse while preparing adsorbent using cassava peel. They maintained a considerably high carbonization temperature of $650{ }^{\circ} \mathrm{C}$ and impregnation ratio of 1.0. The combined effect of time of carbonization and weight ratio on the percentage removal of cyanide is shown in Fig. 1c. From the figure, it is seen that when weight ratio is increased from 1.0 to 3.0 at a constant time of 1 and $1.50 \mathrm{~h}$, the percentage removal decreases from 64.71 to 52.85 and 91.79 to 45.60 , respectively. This may be attributed to the lower impregnation in the presence of low amount of ferric nitrate nonahydrate. Maximum removal of 91.79 is seen when weight ratio and carbonization time have been maintained as 1.0

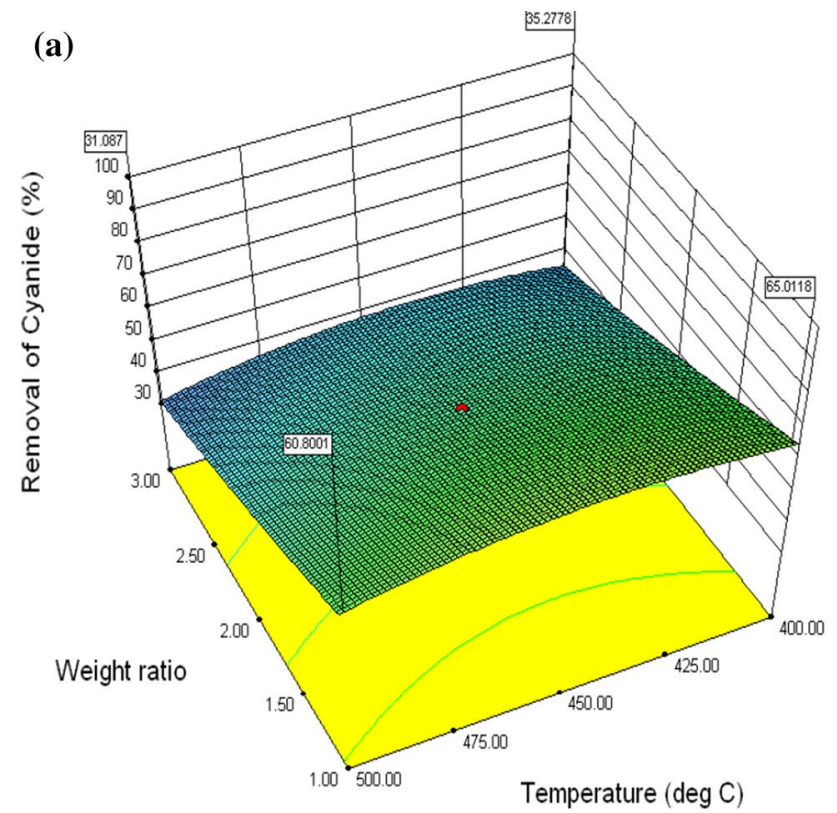

(b)

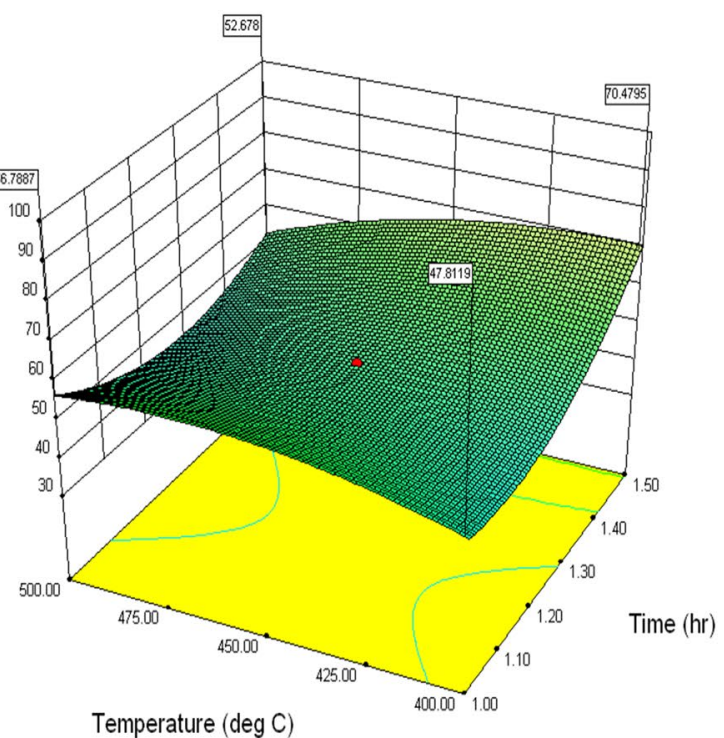

(c)
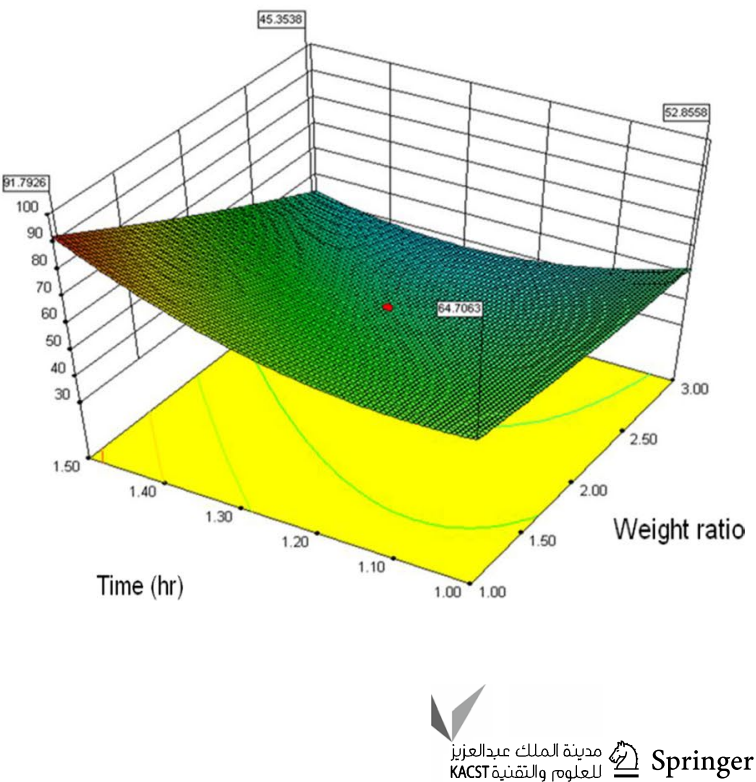
and $1.50 \mathrm{~h}$, respectively. The impregnation ratio has been found to play a vital role in preparation of activated carbon (Ahmadpour and Do 1997). Sudaryanto et al. (2006) used a carbonization time of $1 \mathrm{~h}$ and carbonization temperature $750{ }^{\circ} \mathrm{C}$. They observed a decrease in activated carbon yield with an increase in impregnation ratio.

In order to make the process cost efficient, an optimal set of values for weight ratio, time, and temperature have been

Table 2 Physical properties of ACWI and IIAC

\begin{tabular}{lll}
\hline Properties & ACWI & IIAC \\
\hline Bulk density $\left(\mathrm{kg} \mathrm{m}^{-3}\right)$ & 1002 & 1666.66 \\
Solid density $\left(\mathrm{kg} \mathrm{m}^{-3}\right)$ & 1446 & 4258 \\
Moisture content $(\%)$ & 4.05 & 2.04 \\
BET surface area $\left(\mathrm{m}^{2} \mathrm{~g}^{-1}\right)$ & - & 30.804 \\
\hline
\end{tabular}

(a)

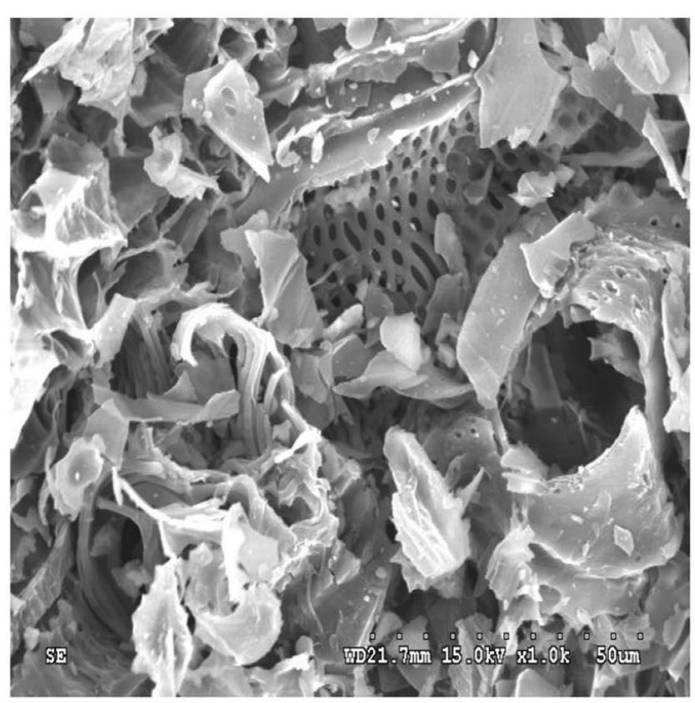

(b)

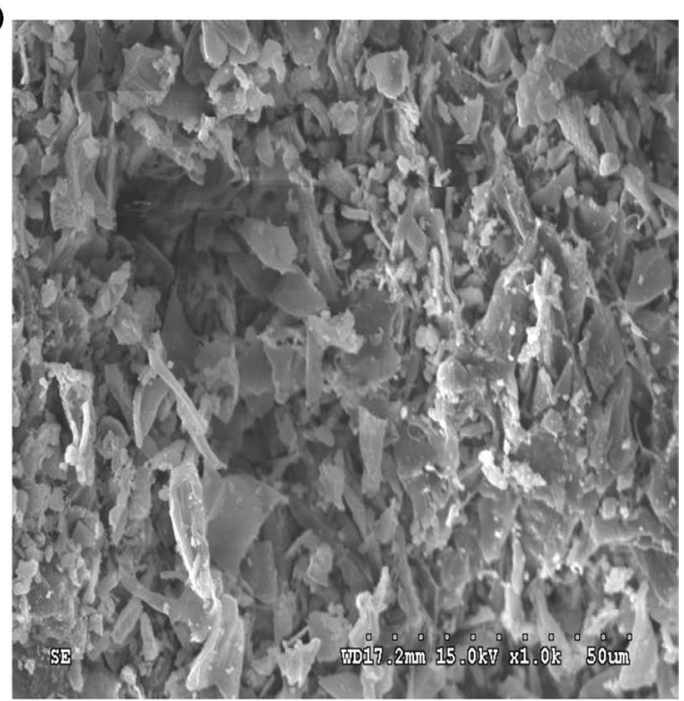

chosen as: 1.0 (Corncob dust and iron(III) nitrate), $1.5 \mathrm{~h}$, and $400{ }^{\circ} \mathrm{C}$, respectively. The sample prepared at this optimum condition is termed as IIAC and employed for further studies on cyanide abatement. Another set of sample has been prepared using Corncob dust under the same carbonization condition but without any iron impregnation, this sample is named ACWI.

\section{Characterization of IIAC}

The physical properties of ACWI and IIAC are shown in Table 2. Higher values of solid and bulk densities of IIAC signify its suitability as adsorbent. Figure $2 a-c$ represents SEM images of ACWI, IIAC before adsorption, and IIAC after adsorption, respectively. Figure $2 \mathrm{a}$ shows ACWI as flask-shaped, porous and having smooth surfaces (Moussavi and Khosravi 2010). Figure 2b shows resemblance

(c)

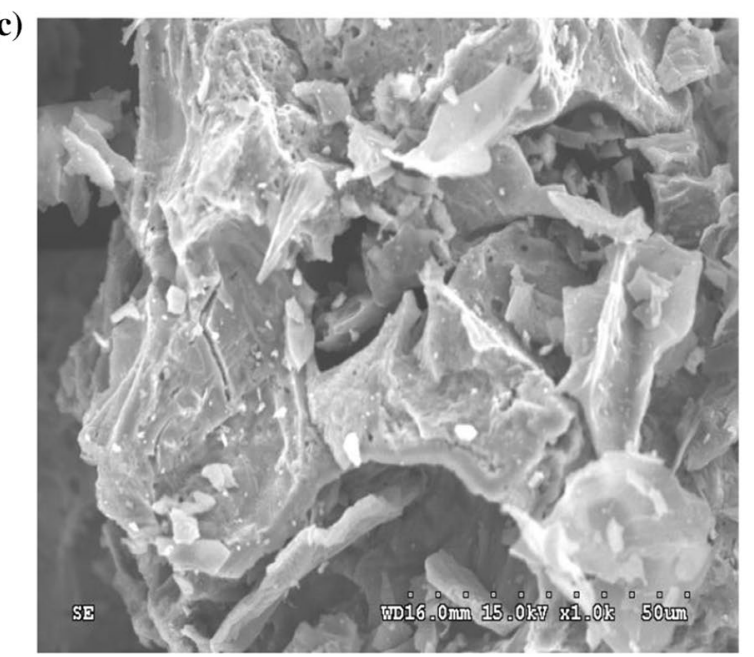

Fig. 2 SEM image of a ACWI b IIAC before adsorption $\mathbf{c}$ IIAC after adsorption 
Table 3 Elemental analysis of EDS

\begin{tabular}{lllll}
\hline Element & ACWI (wt\%) & $\begin{array}{l}\text { Corncob dust without } \\
\text { carbonization }(w t \%)\end{array}$ & $\begin{array}{l}\text { IIAC before adsorp- } \\
\text { tion (wt } \%)\end{array}$ & $\begin{array}{l}\text { IIAC after } \\
\text { adsorption } \\
\text { (wt\%) }\end{array}$ \\
\hline Oxygen $\left(\mathrm{O}_{2}\right)$ & 90.60 & 76.20 & 37.86 & 12.30 \\
Phosphorus $(\mathrm{P})$ & 9.40 & - & 5.30 & 0.19 \\
Zirconium $(\mathrm{Zr})$ & - & 23.26 & - & - \\
Nitrogen $\left(\mathrm{N}_{2}\right)$ & - & 0.54 & - & 0.12 \\
Iron $(\mathrm{Fe})$ & - & - & 56.84 & 83.78 \\
Silica $(\mathrm{Si})$ & - & - & - & 1.80 \\
Aluminum $(\mathrm{Al})$ & - & - & - & 1.80 \\
\hline
\end{tabular}

Table 4 Bonding group analysis for FTIR study

\begin{tabular}{|c|c|c|}
\hline Bonding group & $\begin{array}{l}\text { IIAC before adsorption } \\
\text { wave number }\end{array}$ & $\begin{array}{l}\text { IIAC after } \\
\text { adsorption wave } \\
\text { number }\end{array}$ \\
\hline $\mathrm{NO}_{2}$ & 571 & 567 \\
\hline$-\mathrm{O}-\mathrm{C}-\mathrm{C}-\mathrm{O}-$ & 1253 & - \\
\hline $\mathrm{NH}_{2}$ & 1584 & 1591 \\
\hline$-\mathrm{PH}$ & 2372 & - \\
\hline$-\mathrm{OH}$ & 3406 & 1437 \\
\hline $\mathrm{N}-\mathrm{O}$ & - & 1294 \\
\hline$-\mathrm{CH}_{3},-\mathrm{CH}_{2}$ & - & 2951 \\
\hline
\end{tabular}

with Fig. 2c. However, an enlargement in the structure is noticed in IIAC after adsorption with cyanide in comparison with native IIAC. The SEM images are in agreement with the studies done by Bull and Morgan (2006). The EDS elemental analysis as obtained by EDS study of ACWI, Corncob (without carbonization), and IIAC before and after adsorption is shown in Table 3. IIAC both before and after adsorption shows peaks for iron which is absent in ACWI and Corncob (without carbonization). The presence of iron in IIAC is due to impregnation of iron onto Corncob during carbonization. The nitrogen element in IIAC after adsorption may have come from cyanide. Studies done by Zheng et al. (2014) and Agarwal et al. (2013) are in line with the present EDS study.

The FTIR study has been to observe the alterations in the spectra of IIAC before and after adsorption. Table 4 represents the bonding group analysis of FTIR image of IIAC before and after adsorption. Most of the peaks that happen to be present initially on the surface of adsorbent have diminished; nonetheless, others have changed location after cyanide loading, thus, validating the involvement of functional groups on the adsorbent surface. Ammonium is one of the functional groups actively involved in cyanide adsorption as the wave number shifts from 1584 to $1591 \mathrm{~cm}^{-1}$.

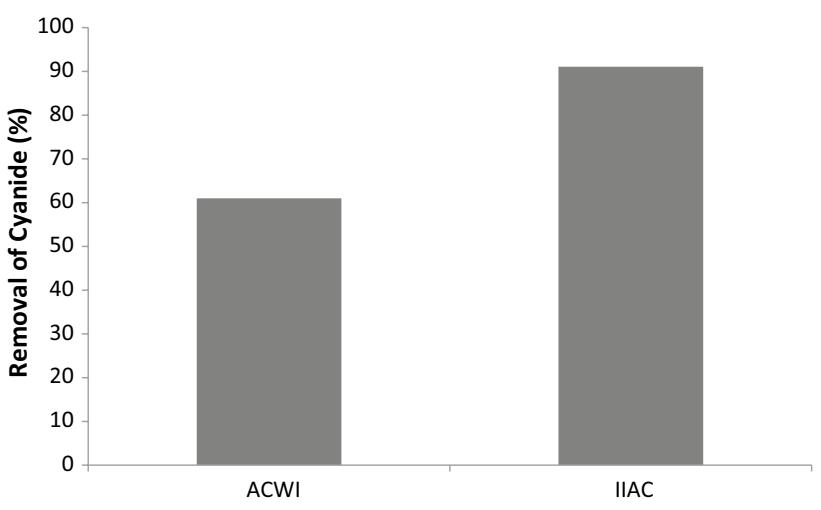

Fig. 3 Comparative study between IIAC and ACWI

\section{Comparative study between ACWI and IIAC for cyanide abatement}

Comparison between IIAC and ACWI has been done on the basis of percentage abatement of cyanide from simulated wastewater. The results obtained are shown in Fig. 3. From the figure, it is seen that ACWI can show $61 \%$ cyanide removal, whereas IIAC is able to remove $91.05 \%$ under identical condition. Therefore, IIAC has been found to be superior to ACWI.

\section{Removal of cyanide-OFAT approach}

\section{Effect of particle size on cyanide removal}

To see the effect of particle size on cyanide removal, particle size has been varied in the range of $45-150 \mu \mathrm{m}$. It is seen that with an increase in particle size, percentage removal decreases, this may be due to decrease in surface area of the particle. Though the smallest one gives sufficiently good removal, the grinding cost is more to get $45 \mu \mathrm{m}$. Therefore, an optimum size of $100 \mu \mathrm{m}$ has been selected. Variation of percentage abatement with time for different particle sizes is shown in Fig. 4a. Agarwal et al. (2013) observed that 

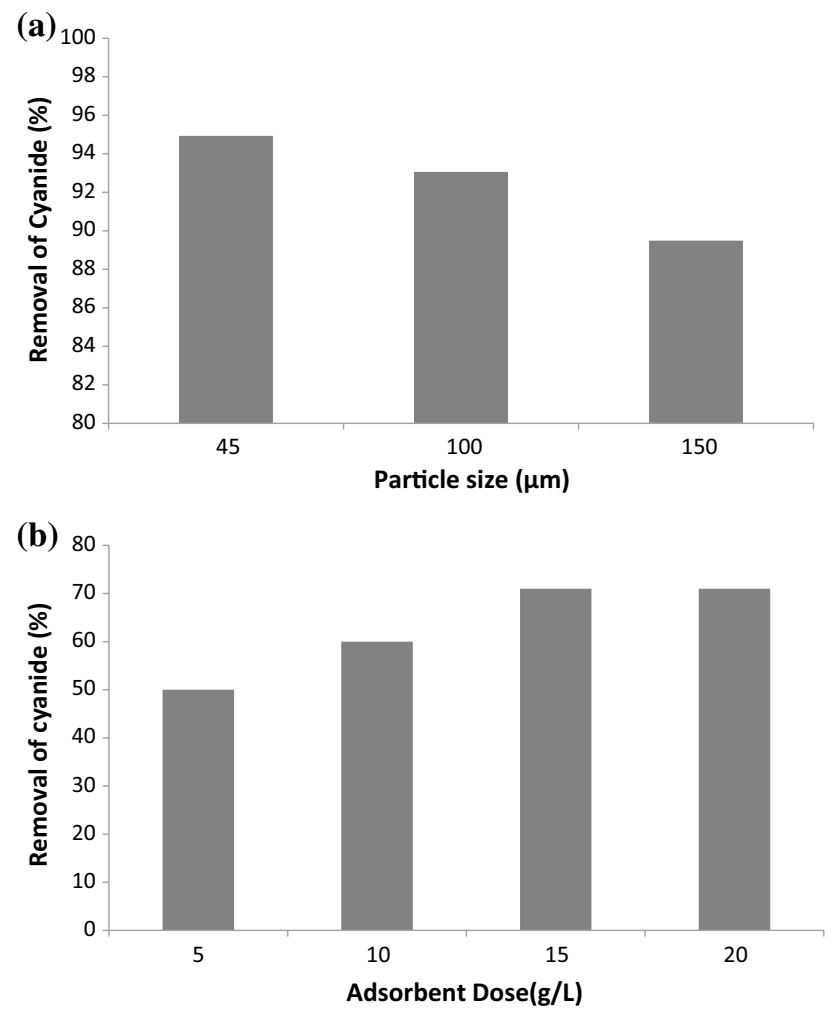

Fig. 4 a Effect of different particle size on removal of cyanide. b Effect of different adsorbent dose on removal of cyanide

particle size of $0.4 \mathrm{~mm}$ showed a removal of $91 \%$, whereas particle size of $0.6 \mathrm{~mm}$ showed $65 \%$ removal.

\section{Effect of amount of adsorbent dose on removal of cyanide}

To examine the effects of adsorbent dosage on the removal of cyanide, adsorbent dose has been varied in the range of 5-20 $\mathrm{g} \mathrm{L}^{-1}$. IC of cyanide, volume of solution, and $\mathrm{pH}$ have been maintained constant as $50 \mathrm{mg} \mathrm{L}^{-1}, 50 \mathrm{~mL}$, and 8 , respectively. Samples have been collected after $3 \mathrm{~h}$ and analyzed for residual cyanide concentration. The result is shown in Fig. 4b. From the figure, it is clear that percentage removal of cyanide is directly dependent on adsorbent dose. When adsorbent dose increases from 5 to $20 \mathrm{~g} \mathrm{~L}^{-1}$, percentage removal of cyanide increases from 49.78 to 71.05 . The effect is more pronounced when low adsorbent dosage was maintained. The initial increase in removal could be attributed to proportional increase in active sites with adsorbent dose. However, above a dose of $15 \mathrm{~g} \mathrm{~L}^{-1}$ removal assumes an asymptotic value. The possible explanation for the behavior could be that there is an overlapping of active sites at high doses which decreases the surface area as was observed by Kilic et al. (2011). Agarwal et al. (2013) showed

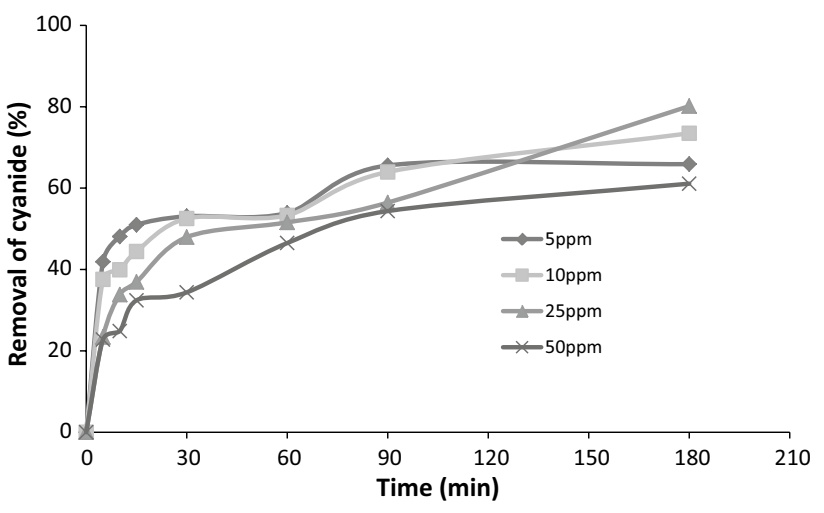

Fig. 5 Variation of removal of cyanide with time considering IC as input parameter

an increase in cyanide removal with increasing adsorbent dosage till $30 \mathrm{mg} \mathrm{L}^{-1}$.

\section{Kinetic study}

The time profile of percentage abatement of cyanide taking IC as a parameter is shown in Fig. 5. From the figure, it is seen that the maximum removal is obtained with lowest concentration of solution. Major removal is obtained within $15 \mathrm{~min}$. When concentration of cyanide increases from 5 to $50 \mathrm{mg} \mathrm{L}^{-1}$, percentage removal of cyanide drops from 65.57 to 54.36. The higher removal at lower concentration may be due to the adequacy of adsorbent. Kumar et al. (2011) showed that at an IC of $10 \mathrm{mg} \mathrm{L}^{-1}$ a removal as high as $93 \%$ was attained, whereas with an IC of $100 \mathrm{mg} \mathrm{L}^{-1}$ a very low removal was obtained.

\section{Analysis of kinetic data with different models}

While analyzing different kinetic models, data obtained during the kinetic study of cyanide removal was used. For this study, IC of cyanide is $25 \mathrm{mg} \mathrm{L}^{-1}$. The parameters values are mentioned in Table 5. From the table, it is seen that the values of correlation coefficient for different kinetic models are different. Due to low correlation coefficient $(<0.9614)$, it can be stated that zero-order, first-order, and pseudo-firstorder cannot analyze the kinetic data suitably. Relatively better correlation coefficients of linearized form of pseudosecond-order equation (0.9614) prove the suitability of the model to predict the experimental data. While studying various literary texts on adsorptive removal of cyanide, it has been seen that most of them follow pseudo-second-order kinetics, and thus the result is in line with the literature present (Agarwal et al. 2013, Moussavi and Khosravi 2010). The adsorption takes place in three steps. Firstly, the adsorbate molecules move from the bulk of the solution to the outer surface of the adsorbent, and thereafter, the molecules 
Table 5 Kinetic models and their linearized expressions

\begin{tabular}{lllll}
\hline Kinetic models & Equation & Linear expression & $R^{2}$ & Parameter values \\
\hline Zero power & $q_{\mathrm{t}}=q_{\mathrm{e}}-k_{0} t$ & $q_{\mathrm{t}}=q_{\mathrm{e}}-k_{0} t$ & 0.9167 & $k_{0}=-0.007$ \\
& $q_{\mathrm{e}}=q_{\mathrm{t}} \exp \left(k_{1} t\right)$ & $\ln q_{\mathrm{e}} / q_{\mathrm{t}}=k_{1} t$ & 0.7831 & $\begin{array}{l}k_{\mathrm{e}}=0.7875 \\
\text { First-order }\end{array}$ \\
& $q_{\mathrm{t}}=q_{\mathrm{e}}-q_{\mathrm{e}} \mathrm{e}^{-\left(k_{2} t\right)}$ & $\ln q_{\mathrm{t}}=\ln q_{\mathrm{e}}-k_{2} t \ln q_{\mathrm{e}}$ & 0.8856 & $k_{\mathrm{e}}=-0.2143$ \\
Pseudo-first-order & & & $k_{2}=0.0092$ \\
& & & & \\
Pseudo-second-order & $q_{t} t=k_{3} q_{\mathrm{e}}^{2} t /\left(1+k_{3} q_{\mathrm{e}} t\right)$ & $\frac{t}{q_{\mathrm{t}}}=\left(\frac{1}{k_{3} q_{\mathrm{e}}^{2}}\right)+\left(t / q_{\mathrm{e}}\right)$ & 0.9614 & $k_{3}=0.063$ \\
& & & $q_{\mathrm{e}}=9.560$
\end{tabular}

Table 6 Parameter values from fitting the adsorption equilibrium data

\begin{tabular}{lll}
\hline Isotherm model & Equation & Parameter values \\
\hline Langmuir model & $q_{\mathrm{e}}=\left(K_{\mathrm{L}} q_{0} C_{\mathrm{e}}\right) /\left(1+K_{\mathrm{L}} C_{\mathrm{e}}\right)$ & $K_{\mathrm{L}}=0.0028 \mathrm{~L} \mathrm{~g}^{-1}$ \\
& & $q_{0}=75.187 \mathrm{mg} \mathrm{g}^{-1}$ \\
& & $R^{2}=0.8911$ \\
Freundlich model & $q_{\mathrm{e}}=K_{\mathrm{F}} C_{\mathrm{e}}^{1 / n}$ & $1 / n=1.7629$ \\
& & $K_{\mathrm{F}}=0.414 \mathrm{mg} \mathrm{g}^{-1}$ \\
& & $R^{2}=0.9891$ \\
\hline
\end{tabular}

of adsorbate diffuse through the interior of the particles of adsorbent (particle diffusion) and finally get adsorbed on the surface of the adsorbent. Any solid-liquid adsorption process is governed by either of the below mentioned three steps: intraparticle diffusion or boundary layer diffusion or adsorption. The present study demonstrates a nonlinear plot, hence proving the nonapplicability of intraparticle diffusion (Behnamfard and Salarirad 2009).

\section{Equilibrium adsorption studies}

An adsorption isotherm is of relevance because it not only reveals solute-surface relationship but also gives the idea about the extent of adsorbate accumulation on the adsorbent surface at a specified temperature (Li et al. 2009). The obtained result during equilibrium study has been fitted to different adsorption isotherm models viz., Langmuir isotherm model and Freundlich isotherm model, and equilibrium parameters are shown in Table 6. The Langmuir isotherm model describes monolayer adsorption of adsorbate onto a homogeneous adsorbent surface, whereas Freundlich isotherm model describes multilayer adsorption of adsorbate onto the surface of adsorbent and also assumes that the stronger binding sites are occupied first and that the binding strength decreases with the increasing degree of site occupation. The values of Freundlich constants $K_{\mathrm{F}}$ and $1 / n$ are related to adsorption capacity and intensity of adsorption, respectively. The value of $1 / n>1$ indicates the favorable adsorption onto the surface of adsorbent. The value of correlation coefficient $\left(R^{2}=0.9891\right)$ for Freundlich model is found to be greater than that obtained for Langmuir isotherm model $\left(R^{2}=0.8911\right)$. Thus, it can be stated that Freundlich isotherm model can explain the experimental data in better way. The result is in agreement with the studies available on adsorption (Agarwal et al. 2013; Zheng et al. 2014) and suggests that the surface of adsorbent for adsorption of adsorbate (cyanide) is heterogeneous. Furthermore, multilayer adsorption of cyanide has been proposed by Freundlich isotherm model. Value of $1 / n>1$ represents a favorable adsorption condition.

\section{Optimization of cyanide removal using IIAC by RSM}

Response surface methodology has been used to get the optimum condition for percentage removal of cyanide from simulated wastewater solution. Three input parameters such as IC of cyanide $\left(\mathrm{mg} \mathrm{L}^{-1}\right)$, adsorbent dose $\left(\mathrm{g} \mathrm{L}^{-1}\right)$, and $\mathrm{pH}$ of the solution have been considered, and percentage removal of cyanide has been chosen as response. The values of +1 and the -1 levels of the input parameters are adsorbent dose: $12-6 \mathrm{~g} \mathrm{~L}^{-1}$, IC of cyanide: $35-20 \mathrm{mg} \mathrm{L}^{-1}$, and $\mathrm{pH}$ of the solution: 8-7. The removal of cyanide was determined by experimentation and is given in Table 7. Design-Expert software (8.0.6) was used for experimental design. The percentage removal varies from 90.29 to $99.99 \%$. Therefore, RSM cannot be used to get optimum condition. To make the process cost-effective, the minimum values are chosen from the table. During kinetic study, it is seen that the maximum percentage removal of cyanide is 80.16 at an IC of $25 \mathrm{mg} \mathrm{L}^{-1}$ and adsorbent dose of $10 \mathrm{~g} \mathrm{~L}^{-1}$. However, kinetic study has been performed at $\mathrm{pH}$ 7. During optimization using RSM, $\mathrm{pH}$ has been varied in the range of $7-9$, and higher removal is obtained with increasing $\mathrm{pH}$. Thus, the optimum condition for removal of cyanide has been chosen at an IC of cyanide of $27.5 \mathrm{mg} \mathrm{L}^{-1}$; adsorbent dose of $3.95 \mathrm{~g} \mathrm{~L}^{-1}$ and $\mathrm{pH}$ of the solution at 7.5. Gebresmati et al. (2017) carried out the optimization study using copper as the impregnating agent. They reported a response of $90.6 \%$ at an IC of $10 \mathrm{mg} \mathrm{L}^{-1}$, contact time of $1 \mathrm{~h}$, and $\mathrm{pH}$ 8. Tyagi et al. (2018) carried out the experiments at $\mathrm{pH} \mathrm{9,} \mathrm{maintaining} \mathrm{the} \mathrm{contact} \mathrm{time} \mathrm{and}$ a cyanide concentration of $45 \mathrm{~min}$ and $50 \mathrm{mg} \mathrm{L}^{-1}$, respectively, attaining a removal of $98.98 \%$. The present study is 
Table 7 Experimental design matrix for removal of cyanide using IIAC

\begin{tabular}{llrll}
\hline Run no. & $\begin{array}{l}\text { Initial concentra- } \\
\text { tion }\left(\mathrm{mg} \mathrm{L}^{-1}\right)\end{array}$ & $\begin{array}{l}\text { Adsorbent dos- } \\
\text { age }\left(\mathrm{g} \mathrm{L}^{-1}\right)\end{array}$ & $\mathrm{pH}$ & $\begin{array}{l}\text { Cyanide } \\
\text { removal } \\
(\%)\end{array}$ \\
\hline 1 & 27.50 & 9.00 & 7.50 & 99.99 \\
2 & 35.00 & 6.00 & 8.00 & 99.51 \\
3 & 35.00 & 12.00 & 7.00 & 97.98 \\
4 & 27.50 & 9.00 & 7.50 & 98.09 \\
5 & 14.89 & 9.00 & 7.50 & 99.99 \\
6 & 40.11 & 9.00 & 7.50 & 99.99 \\
7 & 27.50 & 9.00 & 7.50 & 99.99 \\
8 & 27.50 & 9.00 & 7.50 & 99.99 \\
9 & 20.00 & 6.00 & 8.00 & 99.96 \\
10 & 20.00 & 12.00 & 7.00 & 99.99 \\
11 & 27.50 & 9.00 & 7.50 & 99.99 \\
12 & 20.00 & 6.00 & 7.00 & 99.99 \\
13 & 27.50 & 14.05 & 7.50 & 90.29 \\
14 & 27.50 & 9.00 & 7.50 & 99.99 \\
15 & 35.00 & 6.00 & 7.00 & 99.99 \\
16 & 27.50 & 9.00 & 8.34 & 99.99 \\
17 & 27.50 & 9.00 & 6.66 & 99.62 \\
18 & 35.00 & 12.00 & 8.00 & 98.02 \\
19 & 27.50 & 3.95 & 7.50 & 99.58 \\
20 & 20.00 & 12.00 & 8.00 & 99.51 \\
\hline
\end{tabular}

in agreement with the literature on a diversified range of adsorbents (Wang et al. 2016; Moussavi and Khosravi 2010).

\section{Conclusion}

Corncob, a solid waste, collected locally, has been employed as a precursor for the development of activated carbon. Iron is impregnated during carbonization process. Impregnation increases the adsorption capacity of activated carbon. With the aid of RSM, optimization of the carbonization vis-àvis impregnation conditions has been done. Optimum condition has been found as: weight ratio of Corncob dust to ferric nitrate nonahydrate (1.0), temperature $400{ }^{\circ} \mathrm{C}$, and time $1.50 \mathrm{~h}$ for carbonization. Characterization of IIAC has shown higher solid density than ACWI. EDS analysis confirms the existence of iron on the surface of IIAC. Comparative study between IIAC and ACWI shows that IIAC gives higher removal of cyanide under identical conditions. The effects of IC of cyanide, the weight of adsorbent and particle sizes on the removal of cyanide have been observed. Major removal of cyanide has been obtained within 15 min of operation. Freundlich model has been found to be suitable for the equilibrium study. Though optimization of cyanide abatement has been attempted by employing RSM, the nonvariance of response at different condition makes the ANOVA result nonsignificant. IC, adsorbent loading and $\mathrm{pH}$ are used as input parameters. Same removal has been observed for all input parameters. It has been observed to vary in between 90.29 and $99.99 \%$. Therefore, the optimum condition for removal of cyanide has been chosen as adsorbent dosage of $3.95 \mathrm{~g} \mathrm{~mL}^{-1}$, IC of cyanide $27.5 \mathrm{mg} \mathrm{L}^{-1}$, and $\mathrm{pH}$ 7.5. IIAC has higher potential to remove cyanide from simulated solution. Nonetheless, treatment of industrial wastewater using IIAC in a continuous contactor encompassing the effect of all the parameters is needed.

\section{Compliance with ethical standards}

Conflict of interest The authors do not have any conflicts of interest.

Open Access This article is distributed under the terms of the Creative Commons Attribution 4.0 International License (http://creativeco mmons.org/licenses/by/4.0/), which permits unrestricted use, distribution, and reproduction in any medium, provided you give appropriate credit to the original author(s) and the source, provide a link to the Creative Commons license, and indicate if changes were made.

\section{References}

Agarwal B, Balomajumder C, Thakur PK (2013) Simultaneous coadsorptive removal of phenol and cyanide from binary solution using granular activated carbon. Chem Eng J 228:655-664

Ahmadpour A, Do DD (1997) The preparation of activated carbon from macadamia nutshell by chemical activation. Carbon 35:1723-1732

Behnamfard A, Salarirad M (2009) Equilibrium and kinetic studies on free cyanide adsorption from aqueous solution by activated carbon. J Hazard Mater 170:127-133

Botz MM (2001) Overview of cyanide treatment methods. In: Mining environmental management. Mining Journal Ltd, London, UK, pp 28-30

Bull PA, Morgan RM (2006) Sediment fingerprints. Sci Justice 46(2): 107-124

Chaterjee S, Kumar A, Basu S, Dutta S (2012) Application of response surface methodology for methylene blue dye removal from aqueous solution using low cost adsorbent. Chem Eng J 181:289-299

Dash RR, Balomajumder C, Kumar A (2006) Cyanide removal by combined adsorption and biodegradation process. Iran J Environ Health Sci Eng 3(2):91-96

Dhamo N (1996) Electrochemical oxidation of cyanide in the hydrocyclone cell. Waste Manag 16(4):257-261

Dutta S, Bhattacharyya A, Ganguly A, Gupta S, Basu S (2011) Application of response surface methodology for preparation of lowcost adsorbent from citrus fruit peel and for removal of methylene blue. Desalination 275:26-31

Gebresmati M, Gabbiye N, Sahu O (2017) Sorption of cyanide from aqueous medium by coffee husk: response surface methodology. J Appl Res Technol 15(1):27-35

Gonzalez A, Hendriks ATWM, Van Lier JB, Kruek MD (2018) Pre-treatments to enhance the biodegradability of waste activated sludge: elucidating the rate limiting step. Biotechnol Adv 36:1434-1469 
Gurbuz F, Ciftci H, Akcil A, Karahan AK (2004) Microbial detoxification of cyanide solutions: a new biotechnological approach using algae. Hydrometallurgy 72:167-176

Kilic M, Apaydin-Varol E, Putun AE (2011) Adsorptive removal of phenol from aqueous solutions on activated carbon prepared from tobacco residues: equilibrium, kinetics and thermodynamics. J Hazard Mater 189:397-403

Kumar S, Zafar M, Prajapati JK, Kumar S, Kannepalli S (2011) Modeling studies on simultaneous adsorption of phenol and resorcinol onto granular activated carbon from simulated aqueous solution. J Hazard Mater 185:287-294

Li K, Zheng Z, Huang X, Zhao G, Feng J, Zhang J (2009) Equilibrium, kinetic and thermodynamic studies on the adsorption of 2-nitroaniline onto activated carbon prepared from cotton stalk fibre. J Hazard Mater 166:213-220

Moussavi G, Khosravi R (2010) Removal of cyanide from wastewater by adsorption onto pistachio hull wastes: parametric experiments, kinetics and equilibrium analysis. J Hazard Mater 183(1):724-730

Oliveira LCA, Rios RVRA, Fabris JD, Sapag K, Garg VK, Lago RM (2003) Clay-iron oxide magnetic composites for the adsorption of contaminants in water. Appl Clay Sci 22:169-177

Patil YB, Paknikar KM (2000) Biodetoxification of silver-cyanide from electroplating industry wastewater. Lett Appl Microbiol 30(1):33-37

Priyanka M, Saravanakuma MP (2018) Ultrahigh adsorption capacity of starch derived zinc based carbon foam for adsorption of toxic dyes and its preliminary investigation on oil-water separation. $\mathbf{J}$ Clean Prod 197(1):511-524
Sen S, Nandi S, Dutta S (2018) Application of RSM and ANN for optimization and modeling of biosorption of chromium(VI) using cyanobacterial biomass. Appl Water Sci 8(5):148

Silva JP, Sousa S, Goncalves I, Porter J, Ferreira-Dias S (2004) Modelling adsorption of acid orange 7 dye in aqueous solutions to spent brewery grains. Sep Purif Technol 40:163-170

Sudaryanto Y, Hartono SB, Irawaty W, Hindarso H, Ismadji S (2006) High surface area activated carbon prepared from cassava peel by chemical activation. Biores Technol 97:734-739

Tyagi M, Rana A, Kumari S, Jagadevan S (2018) Adsorptive removal of cyanide from coke oven wastewater onto zero-valent iron: optimization through response surface methodology, isotherm and kinetic studies. J Clean Prod 178:398-407

Wang M, Gao B, Tang D (2016) Review of key factors controlling engineered nanoparticle transport in porous media. J Hazard Mater 318:233-246

Yorgun S, Yildiz D (2015) Preparation and characterization of activated carbons from Paulownia wood by chemical activation with $\mathrm{H}_{3} \mathrm{PO}_{4}$. J Taiwan Inst Chem Eng 53:122-131

Zheng W, Wang Y, Yang L, Li X, Zhou L, Li Y (2014) Novel adsorbent of polymeric complex derived from chelating resin with $\mathrm{Cu}(\mathrm{II})$ and its removal properties for cyanide in aqueous solution. Colloids Surf A Physicochem Eng Asp 455:136-146

Publisher's Note Springer Nature remains neutral with regard to jurisdictional claims in published maps and institutional affiliations. 